\title{
The Impact of Chinese Tourists on Volatility Size Effects and Stock Market Performance in Taiwan
}

\author{
$\underline{\text { C.-L. Chang }}^{\text {ab }}$, H.-K. Hsu ${ }^{c}$ and M. McAleer ${ }^{\text {def }}$ \\ ${ }^{a}$ Department of Applied Economics, National Chung Hsing University, Taiwan. \\ ${ }^{b}$ Department of Finance, National Chung Hsing University, Taiwan. \\ ${ }^{c}$ Department of Finance and Banking, National Pingtung Institute of Commerce, Taiwan \\ ${ }^{d}$ Department of Quantitative Finance, National Tsing Hua University, Hsinchu, Taiwan \\ ${ }^{e}$ Econometric Institute, Erasmus School of Economics, Erasmus University Rotterdam, The Netherlands. \\ ${ }^{f}$ Tinbergen Institute, The Netherlands \\ Email: michael.mcaleer@gmail.com
}

\begin{abstract}
This paper investigates the volatility size effects for firm performance in the Taiwan tourism industry, especially the impacts arising from the tourism policy reform that allowed mainland Chinese tourists to travel to Taiwan. Four conditional univariate GARCH models are used to estimate the volatility in the stock indexes for large and small firms in Taiwan. Daily data from 30 November 2001 to 27 February 2013 are used, which covers the period of Cross-Straits tension between China and Taiwan. The full sample period can be divided into two subsamples, namely prior to and after the policy reform that encouraged Chinese tourists to Taiwan. The empirical findings confirm that there have been important changes in the volatility size effects for firm performance, regardless of firm size and estimation period. Furthermore, the risk premium reveals insignificant estimates in both time periods, while asymmetric effects are found to exist only for large firms after the policy reform. The empirical findings should be useful for financial managers and policy analysts as it provides insight into the magnitude of the volatility size effects for firm performance, how it can vary with firm size, the impacts arising from the industry policy reform, and how firm size is related to financial risk management strategy.
\end{abstract}

Keywords: Tourism, firm size, conditional volatility models, volatility size effects, asymmetry, tourism policy reform 
Chang et al., The impact of Chinese tourists on volatility size effects and stock market performance in Taiwan

\section{INTRODUCTION}

According to the World Tourism Organization (UNWTO), international tourism has experienced continuous expansion and diversification during the past six decades to become one of the largest and fastest-growing economic sectors in the world. International tourist arrivals have shown virtually uninterrupted growth over this period, from a mere 25 million in 1950 to 277 million in 1980, 435 million in 1990, 675 million in 2000 , 935 million in 2010, and a growth of $6.5 \%$ to 996 million in 2011 .

From the supply side of tourism, as stated by UNWTO, emerging economies $(+4.1 \%)$ are tipped to regain the lead in tourism growth of international tourist arrivals in 2012 over the advanced economies $(+3.6 \%)$. By region, with stronger growth, Asia and the Pacific (+7\%) was the best performer in 2012, especially by subregion, with South-East Asia ( $+9 \%$ ) topping the rankings. Excellent international tourist arrivals in this region included Taiwan (R.O.C.), which saw nearly 1 million additional tourist arrivals, which is an impressive growth of $24 \%$. However, from the tourism demand side, Chinese demand for tourism is predicted to quadruple in value in the next ten years (2007-2017), according to the forecasts of the World Travel \& Tourism Council (WTTC). Indeed, the number of Chinese visits abroad reached $47 \mathrm{million}$, which is 5 million more than that of foreign visitors to China for the first time in 2007. At present China ranks a distant second, behind the USA, in terms of tourism demand, but by 2018 it is expected to have closed much of the current gap.

The Taiwan Tourism Bureau has been actively exploring this emerging Chinese tourism market. A series of gradual policy reforms in government policy have been introduced and encouraged, such as Chinese tourists to Taiwan for travel purposes that were approved in July 2008. This was not only a breakthrough for Cross-Straits tourism, but also an important milestone in the history of the development of Taiwan tourism. Since 2005, after much effort on improving the Cross-Straits economic relationship by the Taiwan Government, China has overtaken the USA to become Taiwan's second largest source of imports after Japan. Moreover, China is also Taiwan's number one destination for foreign direct investment. Closer economic links with China brings greater opportunities for the Taiwan tourism industry. As reported by UNWTO, Chinese tourists spent 30 percent more when travelling abroad in 2012 than in 2011.

However, not only in Taiwan, but many countries have been increasing their marketing efforts to lure Chinese tourists, especially given the economic recession and the financial debt crisis that has beset international tourism demand from the leading European and North American countries. In East Asia and South-East Asia, neighboring destinations such as Hong Kong, Macao, South Korea, Japan and Singapore, which are already very popular with Chinese tourists, are redirecting their tourism policies to absorb a greater number of Chinese tourists. Therefore, significant challenges and financial management risks can be expected for the Taiwan tourism industry arising from the increasing competition in Asia.

The connection between international tourism and the financial market would seem to be an important consideration for any country as demand for international tourists would seem to impact significantly on all aspects of the economy and on financial markets. However, research which has empirically documented the link between stock returns, the associated returns volatility, and firm size on the Taiwan tourism industry seems to be scant. There remain many unanswered questions. For instance, from the perspective of financial risk management, is the stock return performance of small firms superior to that of large firms? Is there empirical evidence regarding whether small firms generate greater financial management risk than that of large firms, on average? In particular, what is the impact on financial risk management arising from significant government policy reforms, such as in tourism policy of Chinese tourists being granted permission to travel to Taiwan, on the tourism industry in Taiwan?

Therefore, as financial decisions are generally based upon the trade-off between risk and returns, a primary aim of this paper is to explore how the returns volatility for firm performance varies with firm size, as well as time periods, classified according to the full sample period, as well as prior to and after the introduction of China's tourism reform policy of allowing Chinese tourists to travel to Taiwan. Four conditional volatility models will be used to estimate the volatility size effects arising from the policy reform.

\section{EVALUATING STOCL RETURN VOLATILITY AND VOLATILITY SIZE EFFECTS}

\subsection{Stock Return Volatility}

Financial decisions are generally based on the trade-off between risk and returns. Stock return volatility represents the variability of stock price changes over a period of time. Investors, analysts, brokers, dealers and financial market regulators are concerned with stock return volatility, not just because it is widely used as a measure of risk, but also because they are concerned about "excessive" volatility in which observed 
Chang et al., The impact of Chinese tourists on volatility size effects and stock market performance in Taiwan

fluctuations in stock prices do not appear to be accompanied by any important news about the firm or market as a whole. Therefore, volatility is inherently an important concept in financial markets, as well as in practice in financial risk management and asset allocation. Furthermore, modelling the volatility of a time series may improve the efficiency of the estimates of the parameters of a model and the accuracy of the associated interval forecasts. This is particularly the case when volatility is not constant but rather varies over time.

\subsection{Size Effect of Firm Performance}

The size effect refers to the effect of firm size on investment returns. The common stock of small firms has, on average, higher risk-adjusted returns than that of large firms. This result will hereafter be referred to as the size effect, or small-firm effect. There are several empirical papers in the literature that have found a size effect to be prominent in many countries. Some authors have indicated that the negative relation between abnormal returns and firm size is stable over time. Firm performance may be driven by firm-specific factors, such as firm size. Several papers have shown that other factors may be more important to gauge firm performance than firm-specific factors, such as demand, technological opportunity conditions, and industry effects. Therefore, the empirical issue of performance in stock returns and volatility, as related to the size of a firm, would seem to be in dispute.

\subsection{Proxies for Firm Size and Firm Performance}

This paper uses two proxies, namely stock index returns as a proxy for firm performance, and trade market value of total assets (TA) as a proxy for firm size in order to explore the volatility size effects for firm performance. Empirically, stock returns are the most appropriate proxy of firm performance for all-equity firms because a firms' stock price reflects the value of its future earnings, both from existing assets and their expected growth. Several previous papers have indicated that a firm's total assets (TA) can be taken as a reasonably accurate proxy for firm size.

\section{DATA}

In this section we present the data that will be used in the empirical analysis, and the classifications of tourism stock indexes by the trade market, as a proxy of firm size. The daily closing prices of tourism stock indexes are used from 30 November 2001 to 27 February 2013 for 2,793 time series observations over roughly 12 years. The sources of data are the Taiwan Stock Exchange (TWSE) and Gre-Tai Securities Markets (GTSM). Several previously published papers have indicated that the firm's total assets (TA) can be taken as a proxy for firm size. For measuring the volatility size effect for firm performance, this paper classifies the tourism stock indexes into two categories, namely Large and Small, according to the trade market (a proxy for firm size), which varies according to the requirements of paid-in capital when a public issuer applies for listing. For these reasons, the tourism-related firms listed on the Taiwan Stock Exchange (TWSE) are defined as large firms (that is, Large), whereas the tourism-related firms listed on the Gre-Tai Securities Market are regarded as small firms (that is, Small). The requirement of a firm's paid-in capital for listing on the Taiwan Stock Exchange is at least NT\$600 million, which exceeds the Gre-Tai Securities Market, where a firm's paid-in capital is at least NT\$50 million, at the time a public issuer applies for listing.

\section{UNIVARIATE CONDITIONAL VOLATILITY MODELS FOR FIRM PERFORMANCE}

The standard assumption of a constant variance of random shocks in high frequency economic and financial markets time series data is generally unsustainable empirically. The existence of conditional heteroscedasticity of the random shocks can invalidate standard statistical tests of significance, which assumes that the model is correctly specified. The family of Generalized Autoregressive Conditional Heteroscedasticity (GARCH) models treats the presence of heteroscedasticity as a conditional variance to be modelled. Engle (1982) and Bollerslev (1986) developed a class of models which addresses such concerns, and allows for modelling of both the levels (the conditional first moment) and variances (the conditional second moment) of a time series process. In terms of a univariate model, based on the framework of ARCH, the original specification has been extended in several directions. Four GARCH models will be estimated in this paper, namely the GARCH, GJR (or TARCH), EGARCH, and GARCH-M models. The following discussion briefly presents the model specifications of the conditional mean and the conditional variance.

\subsection{Conditional Mean Specification}

The univariate GARCH model can be used to estimate and forecast risk as a conditional variance process. As mentioned above, the ARCH and GARCH models treat conditional heteroskedasticity as a variance to be modeled rather than as a problem to be corrected. The following conditional expected returns at time $t$, which is given as an $\mathrm{AR}(1)$ process, accommodates a returns process as depending on its own past returns lagged

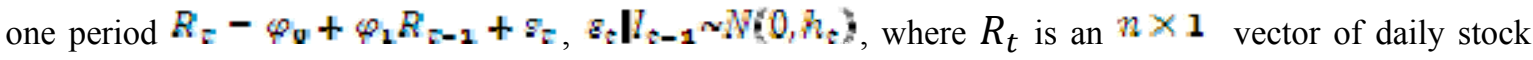


Chang et al., The impact of Chinese tourists on volatility size effects and stock market performance in Taiwan

price returns at time $t$ for each series (in this case, $n=1$ for stock index returns). The $n \times 1$ vector of random errors,$\varepsilon_{t}$, represents the shocks for each series at time $t$, with corresponding $n \times 1$ conditional variance of the residuals of a regression, $h_{t}$. The information available at time $t-1$ is represented by the information set, $I_{t-1}$. The $n \times 1$ vector, $I ?_{0}$, represents the long-term drift coefficients.

\subsection{Conditional Variance Specification}

The alternative conditional volatility models that are used in the empirical analysis include the GARCH model of Bollerslev (1986), the GJR (or TARCH) model of Glosten, Jaganathan and Runkle (1993), and the EGARCH model of Nelson (1991).

\section{EMPIRICAL RESULTS}

The empirical findings for each model will be discussed below. Tourism stock index returns are given as the first difference in $\log$ prices, defined as $R_{t}=100\left(\ln P_{t}-\ln P_{t-1}\right)$, where $P_{t}$ and $P_{t-1}$ are the daily closing prices at time periods $t$ and $t$-1, respectively. Table 1 shows the operational definitions of the log return series used in the paper. Furthermore, as described in Section 1, China's tourism reform policy was such that Chinese tourists were permitted to travel to Taiwan from 13 June 2008 to 18 July 2008. This paper will examine if the risk associated with tourism stock index returns varies according to firm size. Moreover, we will explore how the volatility size effects for firm performance in the Taiwan tourism market may have been affected by the tourism reform policy over different time periods.

It is intended to examine the volatility size effects for different time periods, that is, for the whole sample, as well as prior to and after the tourism reform policy came into effect, for each of two tourism stock index series, namely Large and Small Firms. This paper takes a specific day (1 July, 2008) as the breakpoint, which coincides with the introduction of China's tourism reform policy that allowed Chinese tourists to travel to Taiwan. Therefore, the full sample is divided into two segments, namely Sub-sample A and Sub-sample B, corresponding to the time periods prior to and after the introduction of the tourism policy reform.

This paper applies two stock index returns series, namely Large Firms and Small Firms, to examine the returns and volatility size effects for firm performance during different periods corresponding to three sample sizes, namely the Full sample from 30 November 2001 to 27 February 2013, Sub-sample A from 30 November 2001 to 30 June 2008, and Sub-sample B form 1 July 2008 to 27 February 2013. There is a statistically significant break (or structural change) at the specified breakpoint between the two periods of Sub-samples A and B, which is shown by the Chow breakpoint test. The notation is as follows: (i) Sample F Large for Full sample and Large Firms, (ii) Sample F Small for Full sample and Small Firms, (iii) Sample A Large for Sub-sample A and Large Firms, (iv) Sample A Small for Sub-sample A and Small Firms, (v) Sample B Large for Sub-sample B and Large Firms, and (vi) Sample B Small for Sub-sample B and Large Firms. The empirical results are available from the authors on request.

\subsection{Descriptive Statistics of Returns}

In terms of the Full sample and Sub-sample A, both average returns of Large and Small Firms are positive and low, whereas both average returns of Large and Small Firms in Sub-sample B are negative and very low. In general, all six series mentioned above display significant leptokurtic behaviour, as evidenced by large kurtosis in comparison to the Gaussian distribution. In addition, four of the six series show mild positive skewness, with only Small Firms in Sub-sample B being negatively skewed. The negative skewness statistic implies the series has a shorter right tail than left tail. The Jarque-Bera Lagrange multiplier test statistics indicate that none of these return series is normally distributed, which is not at all surprising for daily financial returns data.

\subsection{Unit Root Test of Returns}

A unit root test examines whether a time series variable is non-stationary. Two well-known tests, the GLSdetrended Dickey-Fuller test and the Phillips-Perron (PP) test, are calculated to test for unit root processes in stock price returns. The unit root tests indicate that all returns series are stationary, which is not particularly surprising. The unit root tests for each individual returns series reject the null hypothesis of a unit root at the $5 \%$ level of significance. However, the same outcome does not hold for two price series, namely the daily closing prices and log daily closing prices. For these two price and log price variables, the unit root tests do not reject the null hypothesis of a unit root at the 5\% level of significance, which implies that the series are non-stationary. Again, this is not a particularly surprising empirical finding. 
Chang et al., The impact of Chinese tourists on volatility size effects and stock market performance in Taiwan

\subsection{Return Spillovers by Firm Size}

The ARCH/GARCH and GARCH-M models enforce a symmetric response of volatility to positive and negative shocks of equal magnitude. However, the asymmetric GJR and threshold EGARCH models provide an alternative perspective to account for the 'volatility-feedback' hypothesis, namely the presence of asymmetric effects. In order to capture returns spillovers, the first step is to consider returns spillovers from the own past returns. For the Large Firms, the empirical results indicate that returns spillovers from own past returns are predictable for all three models for each time period. However, for the Small Firms, this holds only in Sub-sample A, implying that the size effects of the returns spillovers from own past returns existed between the two stock index returns series. It is worth noting the consistent results in that the returns spillovers from the own previous returns for Small Firms are stronger than those of the Large Firms, regardless of the estimated models and time periods. Moreover, both Large and Small Firms do not appear to have risk premium spillovers from the own conditional volatility (or variance) of asset returns, as the estimates of the GARCH-M model are insignificant at the $5 \%$ level, as shown by estimates of the parameter 8 .

\subsection{Volatility Spillovers by Firm Size}

The ARCH effect, $\alpha$, referred to the short-run persistence of shocks to returns, reveal significant estimates for both the Large and Small Firms. It is worth noting that the magnitude of the ARCH effects for Large Firms is relatively stronger than that of Small Firms for both the Full sample and Sub-sample A. However, it holds in reverse for Sub-sample B, where the ARCH effects for Large Firms is relatively weaker than that of Small Firms, with the exception of the EGARCH model. Furthermore, the GARCH (or $\beta$ ) effect indicates the contribution of shocks to long-run persistence (namely, $\alpha+\beta$ ). This suggests that a shock at time $\mathrm{t}$ persists for many future periods because shocks to the conditional variance take a long time to dissipate. Regarding the long-run persistence of shocks with spillover effects from previous impacts, the empirical results show that the estimates for Small Firms is relatively stronger, but with a minor difference, from those of Large Firms for most of the GARCH models. These results suggest that there were not strong size effects of the long-run persistence of shocks for different time periods.

The significant and positive coefficient, I3, namely the asymmetric effect, indicates that a negative shock leads to higher volatility in the future than does a positive shock of the same magnitude. Only positive estimates for Large Firms in Sub-sample B confirm the presence of asymmetry. This suggests that the asymmetric effect varies according to firm size and time period, and only after the tourism policy reform in the case of Large Firms. Alternatively, the significant coefficient, I3, in the EGARCH model represents the sign effects of the standardized residuals. The empirical findings show the sign effect of the standardized residuals, I3, is significantly negative and the absolute value of $I 3$ is lower than for the corresponding estimates $\alpha$, such that the estimates of the absolute value $-0.00742<0.07768$ in the Full sample and in Subsample B. These results suggest that the asymmetric effect is present. However, according to these estimates, there is no leverage effect, whereby negative shocks increase volatility but positive shocks of a similar magnitude decrease volatility. As the stationarity conditions, namely $(\alpha \cap \beta<1$ ), for the GARCH, GJR, and GARCH-M models, and $|\beta|<1$ for the EGARCH model, are confirmed for each returns series examined, all the returns series satisfy the second moment and log-moment conditions. These are sufficient conditions for the Quasi-Maximum Likelihood Estimator (QMLE) to be consistent and asymptotically normal. Therefore, it is valid to conduct standard statistical inference using these estimates.

\section{ACKNOWLEDGMENTS}

For financial support, the first author is most grateful to the National Science Council, Taiwan, and the third author wishes to acknowledge the Australian Research Council and the National Science Council, Taiwan. 
Chang et al., The impact of Chinese tourists on volatility size effects and stock market performance in Taiwan

\section{REFERENCES}

Bollerslev, T. (1986), Generalized autoregressive conditional heteroskedasticity, Journal of Econometrics, 31(3), 307-327.

Engle, R.F. (1982), Autoregressive conditional heteroscedasticity with estimates of the variance of United Kingdom inflation, Econometrica, 50, 987-1007.

Glosten, L.R., Jagannathan, R. and Runkle, D.E. (1993), On the relation between the expected value and the volatility of the nominal excess return on stocks, Journal of Finance, 48, 1779-1801.

Nelson, D.B. (1991), Conditional heteroskedasticity in asset returns: A new approach, Econometrica, 347370 . 